\title{
Effectiveness of adalimumab in the treatment of juvenile idiopathic arthritis associated with uveitis
}

\author{
Elena Zholobova*, Lelia Galstian, MN Nikolaeva, OY Loskutova \\ From 21st European Pediatric Rheumatology (PReS) Congress \\ Belgrade, Serbia. 17-21 September 2014
}

\begin{abstract}
Introduction
Juvenile idiopathic arthritis (JIA) is a chronic autoimmune disease of children and adolescents with primary joints involvement and various manifestations. Uveitis is of extra-articular signs characterized by eye inflammation. Standard antirheumatic drugs in combination with local therapy are effective in $60 \%$. When these drugs are ineffective, genetically engineered drugs are used in JIA with rheumatoid uveitis.
\end{abstract}

\section{Objectives}

This prospective observation was aimed to assessing effectiveness and safety of adalimumab(ADA) in the treatment of juvenile idiopathic arthritis associated with uveitis in patients with severe JIA, prolonged disease and resistance to standard antirheumatic therapy.

\section{Methods}

Among 27 patients with JIA and eye involvement included in the study, 13 children had oligoarticular JIA, 8 children - polyarticular, 6 patients had systemic disease. Study group included 20 girls and 7 boys. Mean age was 7.0 years, age of disease onset was $3.5 \pm 2.07$ years; mean disease duration before ADA administration was $5 \pm 3.6$. Disease onset with initial joint damage was observed in 22 children, with eye involvement - in 5 children. Prior to ADA administration most children had high (III) disease activity. Number of active joints was $10.8 \pm 3.2$, mean ESR was $27.0 \pm 13.37 \mathrm{~mm} / \mathrm{h}, \mathrm{CRP}-2.25 \pm 1.1$ $\mathrm{mg} / \mathrm{dl}$ (ref. $<0.8 \mathrm{mg} / \mathrm{dl}$ ). All 27 patients had active uveitis at the moment of ADA administration. Twenty-four (89\%) patients had bilateral ocular involvement, 3 patients (11\%) - unilateral. Clinical Global Impression -Disease Activity (VAS) score was $76.2 \pm 14.0$,patient/parent score was $65.9 \pm 17.1$. Mean functional disability in patients

\footnotetext{
Departament of Pediatric Rheumatology, First Moscow Medical State
} University I.M. Sechenov, Moscow, Russian Federation before ADA administration was $2.04 \pm 0.57$. Prior to ADA administration all children received immunosuppressive drugs: 26 children (96\%) methotrexate (MTX) $10-15 \mathrm{mg} / \mathrm{m}^{2}$ of body surface per week, 14 children (52\%) received SandimmuneNeoral as monotherapy or in combination with methotrexate, 10 children $(37 \%)$ received oral corticosteroids (CS), 27 children (100\%) received active topical treatment of uveitis.

\section{Results}

After 6 months of adalimumab therapy, humoral activity decreasedin 24 patients (89\%). ESR and CRP also substantially decreased. ACRpedi-30 was achieved in 100.0\% patients, ACRpedi-50 - in 18 patients (67\%), ACRpedi-70 in 13 children (47\%). Uveitis remission was achieved in $41.2 \%$ eyes; $31.4 \%$ showed a significant reduction in inflammatory activity, $27.4 \%$ had no significant dynamics. After 12 months of adalimumab therapy, number of active joints decreased from $10.8 \pm 3.2$ to $4.67 \pm 1.6$. Mean ESR decreased from $27.0 \pm 13.37 \mathrm{~mm} / \mathrm{h}$ to $6 \pm 4.9 \mathrm{~mm} / \mathrm{h}$, CRP from $2.25 \pm 1.1 \mathrm{mg} / \mathrm{dl}$ to $0 \pm 0.34 \mathrm{mg} / \mathrm{dl}$, Clinical Global Impression -Disease Activity (VAS) score decreased from $76.2 \pm 14$ to $37 \pm 12.5$,patient/parent score decreased from $65.9 \pm 17,1$ to $26 \pm 15$. ACRpedi-30 was achieved in $100.0 \%$ patients, ACRpedi-50 - in 20 patients (74\%), ACR pedi-70 in 16 children (59.2\%).

Regarding uveitis, 46,3\% patients had uveitis remission, $16.7 \%$ patients-sub active process. Flares were observed in 6 patients $(22,2 \%)$ often due to noncompliance of combination therapy with adalimumab and methotrexate, while if adalimumab and methotrexate was taken according to the recommended dosing regimen flares were observed only in 4 patients $(14,8 \%)$.

\section{Conclusion}

Overall, treatment with adalimumab (Humira ${ }^{\circledR}$ ) was effective in the vast majority of patients with chronic 
juvenile idiopathic arthritis and uveitis with high clinical and laboratory activity, and resistance to standard antirheumatic therapy.

\section{Disclosure of interest}

None declared.

Published: 17 September 2014

doi:10.1186/1546-0096-12-S1-05

Cite this article as: Zholobova et al: Effectiveness of adalimumab in the treatment of juvenile idiopathic arthritis associated with uveitis. Pediatric Rheumatology 2014 12(Suppl 1):05.

Submit your next manuscript to BioMed Central and take full advantage of:

- Convenient online submission

- Thorough peer review

- No space constraints or color figure charges

- Immediate publication on acceptance

- Inclusion in PubMed, CAS, Scopus and Google Scholar

- Research which is freely available for redistribution

Submit your manuscript at www.biomedcentral.com/submit 